\title{
Op weg naar een gezondere leefstijl
}

Het ontwikkelen van narratieve gezondheidsinterventies voor vrachtwagenchauffeurs

Hans Hoeken, Anniek Boeijinga en José Sanders

TT 39 (2): 149-166

DOI: 10.5117/TVT2017.2.HOEK

\begin{abstract}
On the road to a healthier lifestyle: Developing narrative health interventions for truck drivers

Compared to other professional groups, truck drivers are a low SES group with a relatively unhealthy lifestyle and relatively poor health outcomes. From an analysis of current health interventions aimed at truck drivers, it appears that designers assume that their unhealthy behavior is caused by a lack of motivation to change their unhealthy lifestyle, and that the most effective strategy is to underscore the undesirable consequences of the current behavior as well as the desirable ones of the recommended behavior. This leads to persuasive messages that pose relatively high demands on the target group's cognitive capabilities: hidden premises must be inferred, and the applied argumentation scheme must be identified in order to estimate the arguments' strength. For members of the target group, such argumentative interventions may be too complex. Moreover, many of the target group are already motivated. Many truck drivers wish to live a healthier life, but do not know how to overcome obstacles in their work and private contexts, thus lacking a bridge between intending and acting. We conducted an experiment to investigate the possibilities of narrative health interventions for this target group. The results of this experiment suggest that narrative health interventions may be an effective communication strategy for lower SES target groups.
\end{abstract}

Keywords: narrative persuasion, health communication, narrative intervention, corpus analysis, health literacy 


\section{$1 \quad$ Inleiding $^{1}$}

Er bestaan forse verschillen tussen mensen met een lagere en een hogere Sociaal Economische Status (SES) wat betreft hun gemiddelde levensverwachting en het aantal jaren dat ze in goede gezondheid doorbrengen (CBS, 2012; 2016). Het Nederlandse gezondheidsbeleid is gericht op het verkleinen van deze kloof, waarbij een belangrijke rol is weggelegd voor gezondheidscommunicatie. Die zou mensen moeten informeren over, en aanzetten tot een gezondere leefstijl. Het gegeven dat de verschillen in levensverwachting en gezonde levensjaren tussen lage en hoge SES-groepen niet zijn af- maar juist toegenomen, kan erop wijzen dat deze communicatie onvoldoende is toegesneden op de informatie- en communicatiebehoeften van de lagere SES-doelgroep.

In dit artikel bespreken we een tweetal samenhangende onderzoeken naar gezondheidscommunicatie gericht op een specifieke doelgroep: vrachtwagenchauffeurs. Vrachtwagenchauffeurs kunnen op basis van hun gemiddeld opleidingsniveau en inkomen worden gekwalificeerd als een lagere SES-groep (CBS, 2010). Daarnaast kent deze groep in vergelijking met de rest van de bevolking meer gezondheidsproblemen: zo lijdt een veel groter percentage aan (ernstig) overgewicht, bewegen ze minder en eten ze minder groente en fruit dan wordt aanbevolen (STL, 2016a). Dit leidt tot een hoger arbeidsverzuim en verminderde duurzame inzetbaarheid wat het toekomstig te verwachten tekort aan vrachtwagenchauffeurs in de transportsector nog groter maakt (STL, 2016b).

De doelstelling van het onderzoek was het optimaliseren van de communicatie gericht op het aanzetten van vrachtwagenchauffeurs tot een gezondere leefstijl. In de twee studies stonden de volgende vragen centraal: 1 Wat zijn de kenmerken van de huidige op vrachtwagenchauffeurs gerichte gezondheidscommunicatie-interventies?

2 In welke mate kunnen narratieve gezondheidsinterventies vrachtwagenchauffeurs overhalen om meer te bewegen?

In de volgende twee paragrafen bespreken we eerst het theoretisch kader waarbinnen deze onderzoeken zijn uitgevoerd. Vervolgens worden de opzet en resultaten van de beide studies besproken. We eindigen met een algemene discussie over de implicaties van onze resultaten voor gezondheidsinterventies gericht op doelgroepen met een lagere SES. 


\section{Wat weerhoudt mensen ervan om gezonder te gaan leven?}

De cijfers over overgewicht, onvoldoende bewegen en ongezond eten laten zien dat het merendeel van de vrachtwagenchauffeurs een ongezonde leefstijl heeft. Volgens modellen voor beredeneerd gedrag, zoals het Integrative Model of Behavioral Prediction van Fishbein en Yzer (2003), wordt gedrag bepaald door (1) de benodigde vaardigheden om het gedrag uit te voeren, (2) de intentie om dat te doen en (3) eventuele barrières die het uitvoeren van het gedrag in de weg staan. Als mensen dus bepaald gedrag niet vertonen, kan dat liggen aan (een combinatie van) het ontbreken van de benodigde vaardigheden, obstakels die het vertonen van het gedrag voorkomen en/of een gebrek aan motivatie om het gedrag uit te voeren.

Als de doelgroep het gewenste gedrag niet vertoont, wordt dit vaak toegeschreven aan het ontbreken van de intentie om dat gedrag te vertonen. Communicatie-interventies richten zich dan op de determinanten van de intentie. Ze proberen de doelgroep te overtuigen dat ze in staat zijn om dat gedrag uit te voeren (self efficacy), dat het gewenste gedrag de norm is (perceived norm), maar vooral dat de gevolgen van het aanbevolen gedrag gunstiger zijn dan die van het huidige gedrag om op die manier de attitude van de doelgroep te beïnvloeden. Het idee is dat als deze determinanten maar positief genoeg zijn, de doelgroep vanzelf de intentie vormt om het aanbevolen gedrag uit te voeren en vervolgens zijn gedrag aanpast.

De vraag is of deze benadering altijd geschikt is om mensen aan te zetten tot gezonder gedrag. Schwarzer (2008) onderscheidt in zijn Health Action Process Approach (HAPA)-model voor gezond gedrag drie groepen. Ten eerste zijn daar de actors, de mensen die het gewenste gedrag al uitvoeren. Voor deze groep zou communicatie zich vooral moeten richten op het bevestigen van het huidige gedrag en hen in staat stellen om bij een incidentele terugval (bijv. een sigaret roken na maanden gestopt te zijn) weer het gewenste gedrag op te pakken. De tweede groep zijn de nonintenders: de mensen die niet van plan zijn om hun gedrag aan te passen. Deze groep zit in de motivatiefase en moet gemotiveerd worden om hun leefstijl aan te passen. Volgens Schwarzer spelen daarbij drie determinanten een rol: de mate waarin iemand inschat ernstige gezondheidsrisico's te lopen als gevolg van het huidig gedrag (risk perception), de verwachtingen die hij of zij koestert over wat de gevolgen zullen zijn van het aanbevolen gedrag (outcome expectancies) én de mate waarin hij of zij zich in staat acht het aanbevolen gedrag uit te voeren (action self-efficacy).

Schwarzer (2008) onderscheidt daarnaast een derde groep: de intenders. 
Dit zijn de mensen die wél van plan zijn om hun gedrag aan te gaan passen maar dat voornemen (nog) niet in gedrag hebben omgezet. In dit geval is er sprake van de zogenaamde intentie-gedragskloof. In een meta-analyse van de relatie tussen intenties om gezondheidsgerelateerd gedrag uit te voeren en het daadwerkelijk uitvoeren van dat gedrag, rapporteert Sheeran (2002) dat slechts 53\% van de goede voornemens in gedrag wordt omgezet. Blijkbaar is een positieve intentie vaak onvoldoende voor een gezonde leefstijl. Deze discrepantie tussen intentie en gedrag wordt de intentie-gedragskloof genoemd. Maio, Verplanken, Manstead et al. (2007) noemen twee oorzaken voor het bestaan van deze kloof: mensen komen er niet aan toe om aan het gedag te beginnen (failing to get started) of mensen worden geconfronteerd met barrières die ze niet kunnen overwinnen (getting derailed). Een voorbeeld van het eerste geval is iemand die wil stoppen met alcohol drinken maar dat steeds uitstelt ('morgen stop ik'); van het tweede geval is sprake als deze persoon het moeilijk vindt om 'nee' te zeggen als vrienden hem of haar een pilsje opdringen.

Schwarzer (2008) schetst twee vormen van planning die kunnen helpen om de intentie-gedragskloof te overbruggen. Action planning houdt in dat de doelgroep wordt gestimuleerd om implementatie-intenties te vormen door te vraag te beantwoorden 'wanneer hoe, en onder welke omstandigheden ga ik het gedrag uitvoeren?' Als mensen een dergelijke intentie hebben geformuleerd, neemt de kans fors toe dat ze het gedrag gaan uitvoeren (Gollwitzer \& Sheeran, 2006). Coping planning verwijst naar het vooraf bedenken van strategieën om eventuele obstakels te omzeilen ('als mijn vrienden zeggen dat ik ongezellig ben als ik geen pilsje neem, zeg ik dat ik op donderdag geen alcohol drink') Ook dergelijke plannen leiden tot het overbruggen van de intentie-gedragskloof (Gollwitzer \& Sheeran, 2006).

Uit diepte-interviews met vrachtwagenchauffeurs (Boeijinga, Hoeken, \& Sanders, 2016) blijkt dat deze doelgroep zeker niet alleen uit non-intenders bestaat: velen hebben al pogingen gedaan om gezonder te leven. Er zijn verschillende redenen waarom die pogingen niet zijn geslaagd. Met name in de context van 'meer bewegen' lijken daarbij vooral obstakels in de werk- en gezinssituatie van belang. Daarnaast zijn er ook non-intenders onder de chauffeurs: zij zien het nut van een gezondere leefstijl niet in omdat ze hun eigen gezondheidssituatie vergelijken met die van collega's die in hun ogen (nog) slechter af zijn. Ook bleken veel chauffeurs zich te ergeren aan de stereotype wijze waarop chauffeurs worden afgebeeld in de media en gezondheidsinterventies.

Gezien de cijfers over het ongezonde gedrag van vrachtwagenchauffeurs lijken de bestaande communicatieve interventies er onvoldoende in 
te slagen om de leefstijl van vrachtwagenchauffeurs aan te passen. Mogelijk ligt de verklaring in een verkeerde focus. Het benadrukken van gedragsgevolgen heeft vooral zin bij non-intenders; intenders hoeven hier niet van overtuigd te worden. Omgekeerd heeft het stimuleren van plannen maken vooral zin bij intenders en minder bij non-intenders. Het is daarom interessant om te onderzoeken wat voor informatie de huidige gezondheidsinterventies bevatten.

\section{$3 \quad$ Welke vorm past het beste bij de doelgroep?}

Behalve de inhoud van de interventies zou ook de vorm een probleem kunnen vormen voor hun effectiviteit. Een lagere SES gaat vaak samen met een lagere gezondheidsgeletterdheid (Twickler, Hoogstraten, Reuwer, et al., 2009). Gezondheidsgeletterdheid wordt gedefinieerd als 'the cognitive and socials skills which determine the motivation and the ability of individuals to gain access to, understand and use information in ways which promote and maintain good health' (WHO, 1998). Het is voorstelbaar dat vrachtwagenchauffeurs moeite hebben met het begrijpen van de communicatieve interventies.

Schellens en De Jong (2004) analyseerden brochures van overheden en organisaties gericht op gedragsbeïnvloeding. Zij concludeerden dat deze vooral gebruikmaakten van argumentatie om hun doel te bereiken; veelal werd gewezen op de positieve gevolgen van het aanbevolen gedrag en de negatieve van het huidige gedrag. Schellens en De Jong wijzen erop dat het de lezers van deze brochures niet gemakkelijk wordt gemaakt om de aangevoerde argumenten zorgvuldig te evalueren omdat die argumenten veelal als feitelijke informatie worden gepresenteerd. Daardoor moeten lezers eerst identificeren welke informatie als argument kan worden beschouwd. Voor de evaluatie van dat argument moet vervolgens het relevante argumentschema worden geïdentificeerd want de evaluatiecriteria verschillen per argumenttype: bij analogie-argumentatie spelen overeenkomsten en verschillen tussen de vergeleken gevallen een belangrijke rol, bij pragmatische argumentatie gaat het om de waarschijnlijkheid en wenselijkheid van het gevolg waarnaar wordt verwezen. Zo wordt regelmatig op een gedragsgevolg gewezen, maar blijft de (on)wenselijkheid van dat gevolg onbesproken. Als de gezondheidsinterventies gericht op vrachtwagenchauffeurs op deze manier zijn opgezet, dan zouden ze wellicht te complex zijn voor deze groep gezien hun lagere gezondheidsgeletterdheid. Een andere mogelijkheid is dat deze expliciete inferenties niet gemaakt worden bij het 
lezen van een persuasieve tekst, zeker als het om lezers met lage SES/geletterdheid gaat; een oppervlakkige verwerking zal de overtuigingskracht van deze argumentatieve teksten niet ten goede komen, noch leiden tot stabiele attitudes.

De door Schellens en De Jong (2004) geanalyseerde brochures behoren tot het argumentatieve genre: het zijn zakelijke documenten met een voor het publiek duidelijk informatief en/of persuasief doel. Naast het argumentatieve genre wordt het verhalende of narratieve genre onderscheiden. Toolan (2001, p. 8) definieert een narratief als 'a perceived sequence of non-randomly connected events, typically involving, as the experiencing agonist, humans or quasi-humans, or other sentient beings, from whose experience we humans can 'learn'.' Dit leren kan zich uiten in aanpassingen in opinies en gedrag. Twee meta-analyses laten zien dat verhalen inderdaad invloed kunnen uitoefenen op de overtuigingen, attitudes, intenties en het gedrag van het publiek (Braddock \& Dillard, 2016; Shen, Sheer, \& Li, 2015).

Deze meta-analyses bevestigen de ideeën van verschillende onderzoekers over de belofte van verhalen voor het beïnvloeden van gezondheidsgedrag (bijv. Green, 2006; Kreuter et al., 2007). Deze belofte was gebaseerd op verschillende overwegingen. In de eerste plaats zijn verhalen interessanter dan betogen, waardoor de kans toeneemt dat de doelgroep aandacht besteedt aan de boodschap. Daarnaast zorgt de uitgebreide ervaring die mensen hebben met het narratieve genre ervoor dat ze sterk ontwikkelde schema's hebben die het gemakkelijk maken om een verhaal te begrijpen én te onthouden. Ten slotte is de kans op weerstand groter bij een evident argumentatieve boodschap dan bij een verhaal. Omdat het persuasieve doel van een verhaal minder duidelijk is, zou de kans op een diepe verwerking van argumentatie met het risico van verwerping ervan, minder groot zijn.

Verhalen kunnen daarbij zowel relevant zijn voor non-intenders als voor intenders. Moyer-Gusé (2008) beargumenteert dat een verhaal waarin een personage het ongewenste gedrag vertoont en daarvan de negatieve gevolgen ervaart, non-intenders ervan kan overtuigen dat men zelf óók een reëel risico loopt. Omgekeerd kan een verhaal waarin een personage de vruchten plukt van het aanbevolen gedrag, de non-intenders overtuigen van de wenselijke uitkomsten van het aanbevolen gedrag. Daarbij zou van belang zijn dat de doelgroep zich herkent in het verhaalpersonage. Verhalen bieden daarnaast voor intenders voorbeelden van het omgaan met obstakels bij pogingen om de intentie om te zetten in gedrag. Op die manier zou het verhaalpersonage als rolmodel kunnen fungeren voor het omgaan met barrières. 
Uitgaande van de hiervoor besproken literatuur willen we eerst de huidige gezondheidsinterventies gericht op vrachtwagenchauffeurs bestuderen, om vast te stellen op welke determinanten van het gezondheidsgedrag deze interventies zich richten en op welke wijze men deze gedragsdeterminanten probeert te beïnvloeden: worden daarvoor vooral argumenten aangedragen, of vertelt men verhalen over het wedervaren van vrachtwagenchauffeurs? Boeijinga, Hoeken en Sanders (2017) hebben deze vragen proberen te beantwoorden. In de volgende paragraaf wordt een korte samenvatting van de bevindingen gegeven.

\section{$4 \quad$ Bestaande interventies gericht op vrachtwagenchauffeurs}

In deze paragraaf staan de volgende twee vragen centraal:

1 Op welke determinanten van het gezondheidsgedrag richten deze interventies zich?

2 Welke communicatievorm of -vormen worden ingezet om die determinanten te beïnvloeden?

Om deze vragen te beantwoorden wordt een analyse uitgevoerd van de bestaande interventies gericht op het beïnvloeden van het gezondheidsgedrag van vrachtwagenchauffeurs.

\subsection{Methode}

Er werden 21 gezondheidsinterventies geanalyseerd. Deze interventies voldeden aan de volgende criteria: ze waren gericht op beïnvloeding van het gezondheidsgedrag van vrachtwagenchauffeurs en waren verschenen in de periode 2000-2015. De interventies waren alle geprint, bevatten afbeeldingen en varieerden sterk in lengte ( 1 tot 32 pagina's) en in vorm (posters, folders, brochures). Onze zoektocht leverde geen audio, audiovisuele of digitale interventies op. Vijftien interventies waren gericht op het bevorderen van gewenst gedrag zoals een goede houding en gezonde voedingspatronen; de overige zes waren gericht op het ontmoedigen van ongewenst gedrag zoals roken en alcoholgebruik. De interventies waren geproduceerd door, of ontwikkeld in samenwerking met organisaties uit de Nederlandse transportindustrie, zoals arbodiensten en het Sectorinstituut voor Transport en Logistiek.

Elke interventie werd gecodeerd op de aanwezigheid van informatie gericht op gedragsdeterminanten waarbij determinanten die relevant 
waren voor non-intenders onderscheiden werden van determinanten die relevant waren voor intenders. Tot de non-intenders determinanten behoorde informatie over de kans op het oplopen van ernstige gezondheidsproblemen als gevolg van het huidige gedrag (risk perception), informatie over de te verwachten gevolgen van het aanbevolen gedrag (outcome expectancies) en informatie over de uitvoerbaarheid van het aanbevolen gedrag (action self efficacy). Voor de intenders werd gecodeerd op informatie over het wanneer, waar en hoe van het uitvoeren van het aanbevolen gedrag (action planning), over hoe om te gaan met obstakels bij het uitvoeren van het aanbevolen gedrag (coping planning) en hoe om te gaan met een terugval (maintenance self-efficacy). Gegeven de grote verschillen in lengte werd alleen gecodeerd of informatie over een bepaalde determinant voorkwam, niet hoe vaak dat het geval was.

Alle interventies bleken argumentatief van aard en bevatten argumentatie. Voor elke interventie werd bepaald of argumentatie werd ingezet ter ondersteuning van het standpunt. Vervolgens werd het argumenttype bepaald aan de hand van de pragma-dialectische classificatie van argumentschema's (Garssen, 2001). Het dialectisch uitgangspunt van deze theorie maakt het mogelijk om van meet af rekening te houden met concrete of mogelijke tegenargumenten. Daarbij werd bepaald in hoeverre alle relevante elementen van het argument expliciet aanwezig waren. Zowel de analyse van de informatie gericht op Health Action Process Approach (HAPA)-determinanten als de argumentatie-analyse werd door twee beoordelaars uitgevoerd en de uiteindelijke indeling kwam na uitgebreid overleg tot stand.

\subsection{Resultaten}

Uit de analyse van de HAPA-determinanten bleek dat de focus van de interventies met name op de non-intenders-determinanten lag. In 18 van de 21 interventies was informatie opgenomen gericht op het vergroten van de self efficacy, in 16 werd informatie over de te verwachten gevolgen gegeven en 12 interventies bevatten informatie gericht op het verhogen van de risicoperceptie. Daarentegen werd er weinig informatie verstrekt die gericht was op de determinanten van intenders: 9 van de 21 interventies bevatten informatie gericht op action planning. In geen van de interventies werd aandacht besteed aan coping planning.

Uit de argumentatie-analyse bleek dat er vooral gebruik werd gemaakt van pragmatische argumentatie, argumentatie op basis van voorbeelden (veelal opsomming van voorbeeldoorzaken of voorbeeldgedrag), argumentatie op basis van autoriteit en argumentatie op basis van oorzaak naar 
gevolg. In veel gevallen werd één van de premissen impliciet gelaten. Het identificeren van deze verzwegen premisse is noodzakelijk om te kunnen bepalen om welk argumentschema het gaat en welke evaluatiecriteria daarbij van toepassing zijn. In Figuur 1 wordt duidelijk hoe die pragmatische argumentatie wordt ingezet, maar ook hoe impliciet de boodschap is die wordt verkondigd: de vrachtwagenchauffeur moet infereren dat deze gezonde eetlust ongezond is, en dat het essentieel is dat hij zijn gedrag verandert van 'gezond' ongezond naar 'echt' gezond eten.

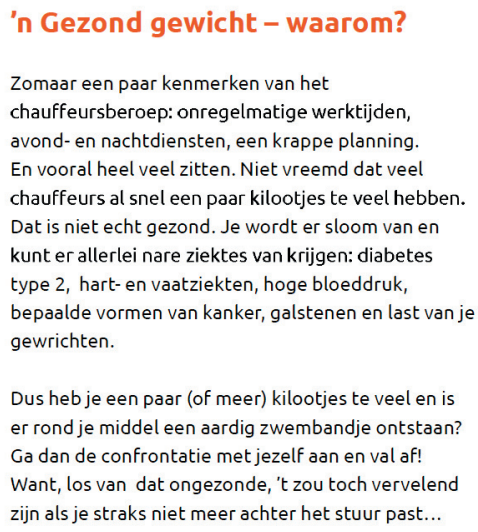

Dus heb je een paar (of meer) kilootjes te veel en is er rond je middel een aardig zwembandje ontstaan? Ga dan de confrontatie met jezelf aan en val af! Want, los van dat ongezonde, 't zou toch vervelend zijn als je straks niet meer achter het stuur past...

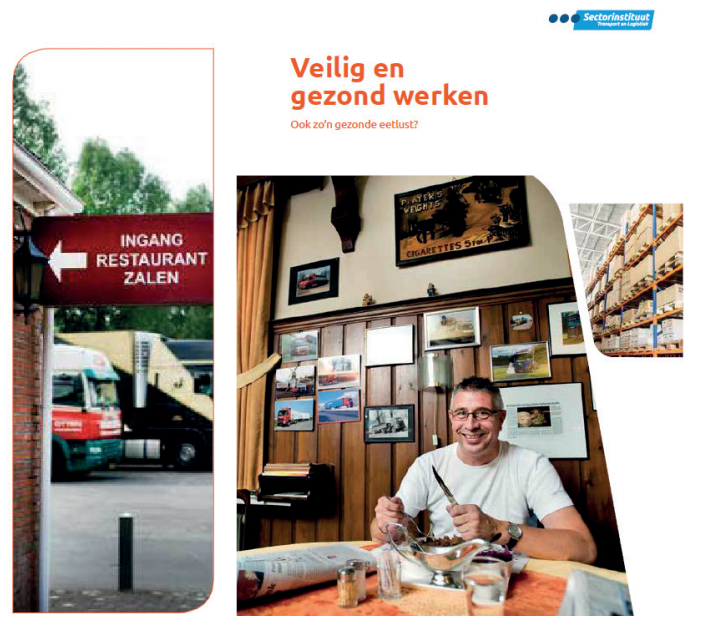

Figuur 1 Een voorbeeld van impliciete argumentatie

\subsection{Conclusies}

Op basis van deze analyse lijkt de conclusie gerechtvaardigd dat de ontwikkelaars van deze interventies vrachtwagenchauffeurs zien als non-intenders die gemotiveerd moeten worden om hun ongezonde gedrag in te wisselen voor een gezondere leefstijl: een beeld dat werd bevestigd in bijeenkomsten met (gezondheids)professionals uit de transportsector. Om dat doel te bewerkstelligen wordt informatie gegeven die gericht is op het verhogen van de risicoperceptie, het benadrukken van de positieve gevolgen van het aanbevolen gedrag en over de uitvoerbaarheid van dat gedrag. De informatie voor intenders is veel beperkter: er wordt in minder dan de helft van de interventies informatie ter ondersteuning van action-planning verstrekt; het omzeilen van barrières blijft volledig onbesproken.

Geen van de interventies is in een narratieve vorm gegoten. Net als in Schellens en De Jong (2004) wordt vooral gebruikgemaakt van pragmatische argumentatie, argumentatie op basis van autoriteit en argumentatie 
op basis van voorbeelden. En ook voor de interventies gericht op vrachtwagenchauffeurs geldt dat er gebruik wordt gemaakt van verzwegen premissen. Dit stelt hoge eisen aan de cognitieve vaardigheden van de doelgroep: wil men bij hen een stabiele attitude creëren door diepere verwerking, dan moeten zij de verzwegen premissen infereren, het gehanteerde argumentatieschema identificeren én vervolgens de relevante evaluatiecriteria toepassen. Juist voor een groep met een lagere gezondheidsgeletterdheid kan dit voor problemen zorgen.

\section{Effecten van narratieve gezondheidsinterventies}

Narratieve interventies zouden juist voor een lagere SES-doelgroep een effectieve strategie kunnen vormen. De Graaf, Sanders en Hoeken (2016) hebben recente narratieve gezondheidsinterventiestudies in kaart gebracht en concluderen dat het een bijzonder heterogene verzameling is. Interventies verschillen sterk wat betreft de inhoud, vorm, lengte, medium en de mate waarin het persuasieve karakter van de interventie expliciet is. Ook zijn er grote verschillen in effectiviteit tussen de verschillende interventies wat waarschijnlijk samenhangt met deze verschillen in kenmerken.

In Boeijinga et al. (in druk) werden twee specifieke narratieve interventies voor vrachtwagenchauffeurs onderzocht. In de eerste plaats werd een verhaal ontwikkeld waarin een reëel gevaar van het ongezonde gedrag werd beschreven. Dit gevaarverhaal zou bij non-intenders tot een hogere risicoperceptie, negatieve emoties en positievere intentie tot gezonder gedrag moeten leiden. Daarnaast werd een verhaal ontwikkeld waarin een vrachtwagenchauffeur vertelt dat hij gezonder is gaan leven en hoe hij de obstakels heeft omzeild die hij daarbij tegen is gekomen. Dit strategieverhaal zou intenders moeten sterken in hun action en coping planning, hetgeen ook zou moeten leiden tot een positieve intentie om het gezondere gedrag ten uitvoer te brengen. In deze studie stond niet zozeer de relatieve effectiviteit van deze narratieve interventies centraal - welk verhaal leidt tot een positievere intentie? - maar de vraag of deze verschillende interventies langs verschillende routes de intenties van de chauffeurs beïnvloeden.

Daarnaast werd bestudeerd of het medium een verschil maakte: de narratieve interventies werden aangeboden in geschreven vorm maar ook als luisterverhaal. Shen et al. (2015) concluderen op basis van hun metaanalyse dat gedrukte narratieve interventies minder impact hebben dan auditieve of audio-visuele narratieven. Braddock en Dillard (2016) vinden 
geen verschil tussen de verschillende media waarin narratieven werden aangeboden. Gezien de lagere geletterdheid van de doelgroep is het voorstelbaar dat een auditief aangeboden verhaal gemakkelijker te verwerken is dan een geschreven versie. Het gemak waarmee het verhaal wordt verwerkt, zou de mate waarin het publiek wordt getransporteerd naar de wereld van het verhaal kunnen versterken. Omdat narratieve betrokkenheid essentieel is voor het persuasieve effect van narratieven (zie bijv. Busselle \& Bilandzic, 2009; De Graaf, Hoeken, Sanders, \& Beentjes, 2009; Green \& Brock, 2000), veronderstelden we dat de auditieve narratieve interventies sterker werken dan de geschreven interventies. In Boeijinga et al. (in druk) werden dus de volgende vragen gesteld:

Onderzoeksvraag 1: In hoeverre leiden verschillende narratieve interventies via andere routes tot een positievere intentie om gezonder te leven? Onderzoeksvraag 2: In hoeverre zijn de effecten van auditieve narratieve interventies sterker dan die van geschreven interventies?

\subsection{Methode}

Op basis van de interviews zoals gerapporteerd in Boeijinga et al. (2016) werden twee verschillende verhalen ontwikkeld. In het gevaarverhaal vertelde een vrachtwagenchauffeur over de gezondheidsklachten die hij krijgt als hij de wagen aan het lossen is. Na gebeld te hebben met zijn vrouw en overleg met zijn planner kan hij de volgende dag tijd maken om naar de huisarts te gaan. Die stuurt hem direct door naar het ziekenhuis waar hij snel wordt geopereerd omdat een van zijn aders bijna geheel is dichtgeslibd. Zijn cardioloog maakt hem duidelijk dat zijn hartklachten het gevolg waren van zijn leefstijl en dat het veel slechter had kunnen aflopen. Het strategieverhaal toont een vrachtwagenchauffeur die gezonder wil gaan leven. Hij vertelt daarbij hoe hij dat bewegen heeft ingebouwd in zijn dagelijkse routines zoals een of twee keer per week op de fiets naar het werk en wandelen met zijn vrouw. Hij beschrijft ook hoe zwaar het begin was en dat hij echt heeft moeten doorzetten, maar ook blij is dat hij dat heeft gedaan.

Beide verhaallijnen waren gebaseerd op authentieke verhalen van chauffeurs en werden zoveel mogelijk in hun woorden verteld. Vervolgens werden ze voorgelegd aan een aantal chauffeurs én aan de redactieleden van $T O N$, een tijdschrift dat zich richt op werknemers in de transportsector. Op basis van de commentaren werden de verhalen nog verder aangepast. Vervolgens werd het verhaal voorgelezen door drie verschillende mannen. De opnames werden voorgelegd aan een aantal chauffeurs en de 
versie waarvan de stem als meest representatief voor een vrachtwagenchauffeur werd gezien, is uiteindelijk opgenomen in het onderzoek.

In de vragenlijst werden zowel vragen gesteld over de leeservaring als over de verschillende determinanten uit het HAPA-model. Bij de leeservaring werd de aandacht voor het verhaal ( $n=4, \alpha=.74)$, narratieve aanwezigheid ( $\mathrm{n}=7, \alpha=.81$ ), identificatie met de hoofdpersoon ( $\mathrm{n}=6, \alpha=.85$ ), waargenomen realisme ( $n=4, \alpha=.84)$, weerstand $(n=5, \alpha=.75)$, ervaren positieve (blij) en negatieve emoties $(\mathrm{n}=5, \alpha=.84)$, verwerkingsplezier ( $\mathrm{n}$ $=5, \alpha=.75)$ gemeten. Bij de HAPA-determinanten ging het om de risicoperceptie $(\mathrm{n}=4, \alpha=.82)$, verwachtingen over gevolgen $(\mathrm{n}=9, \alpha=.90)$, uitvoerbaarheid van het gedrag $(\mathrm{n}=7, \alpha=.85)$, action planning $(\mathrm{n}=5, \alpha=$ .94), coping planning ( $\mathrm{n}=4, \alpha=.86$ ) en de intentie om het gedrag uit te voeren ( $n=4, \alpha=.86$ ). Een uitgebreide beschrijving van de gehanteerde maten is te vinden in Boeijinga et al. (in druk).

Aan het onderzoek namen 120 vrachtwagenchauffeurs deel (118 mannen, 2 vrouwen). De leeftijd varieerde van 19 tot 67 met een gemiddelde van 43 jaar. Gemiddeld was men 21 jaar vrachtwagenchauffeur. Een onderzoeksessie nam tussen de twintig en dertig minuten in beslag. De chauffeurs werd verteld dat ze op elk moment en zonder opgaaf van reden konden stoppen met het onderzoek en dat gegevens anoniem werden verwerkt. Zij ontvingen 7,50 euro voor hun deelname.

\subsection{Resultaten}

De leeservaringsvariabelen en de HAPA-determinanten werden geanalyseerd met behulp van twee afzonderlijke tweeweg MANOVA's met Verhaaltype (gevaar, strategie) en Medium (geschreven, gesproken) als factoren. In beide analyses bleek Medium geen invloed te hebben, noch als hoofdeffect (verhaalervaring: Wilks' $\lambda=.876, F(11,106)=1.365, p=.20$; HAPA-variabelen: Wilks' $\lambda=.931, F(6,111)=1.38, p=.23)$ noch in interactie met verhaaltype (verhaalervaring: Wilks' $\lambda=.862, F(11,106)=1.545, p=.124$; HAPA-variabelen: Wilks' $\lambda=.959, F(6,111)=0.80, p=.57)$.

Wel traden er hoofdeffecten van Verhaaltype op bij verhaalervaring (Wilks' $\left.\lambda=.684, F(11,106)=4.46, p<.001, \eta^{2}=.316\right)$ en HAPA-variabelen (Wilks' $\lambda=.880, F(6,111)=2.5^{2}, p=.025, \eta^{2}=.120$ ). Bij de verhaalervaring bleek dit effect uitsluitend op te treden voor de ervaren emoties: het gevaarverhaal riep sterkere negatieve emoties op $(M=3.12, S D=0.69)$ dan het strategieverhaal $\left(M=2.45, S D=0.77 ; F(1,116)=24.71, p<.001, \eta^{2}=.176\right)$ terwijl het omgekeerde gold voor de mate waarin de verhalen positieve emoties opriepen (gevaarverhaal: $M=2.49, S D=0.56$; strategieverhaal: $M$ $\left.=2.24, \mathrm{SD}=0.66 ; F(1,116)=4.71, p=.032, \eta^{2}=.039\right)$. 
In vergelijking met het gevaarverhaal, bleek het strategieverhaal bij de HAPA-determinanten tot een positievere intentie $(M=3.06, S D=0.62$ versus $\left.M=3.34, S D=0.71 ; F(1,116)=7.90, p=.006, \eta^{2}=.064\right)$, en hogere scores op action planning $(M=3.34, S D=0.77$ versus $M=2.90, S D=0.95 ; F$ $\left.(1,116)=8.23, p=.005, \eta^{2}=.066\right)$ en outcome expectancies te leiden $(M=$ $3.67, S D=0.59$ versus $\left.M=3.34, S D=0.71 ; F(1,116)=7.90, p=.006, \eta^{2}=.064\right)$. De risicoperceptie zelf bleek niet beïnvloed te zijn door de aard van het verhaal.

Met behulp van Hayes' PROCESS macro (model 4; 10.000 bootstraps, 95\% betrouwbaarheidsinterval) werd vervolgens een mediatie-analyse uitgevoerd om te zien hoe de aard van het verhaal invloed had op de intentie om meer te bewegen. Intentie was daarbij de afhankelijke variabele, de afhankelijke variabelen waarvoor significante effecten waren gevonden, werden als potentiële mediatoren ingevoerd, en de overige variabelen werden als controlevariabelen opgenomen. Het totale effect van verhaalversie op de intentie was ook hier significant $(b=.366$, CI $[.087,645])$. Uit de mediatie-analyse bleek dat zowel action planning als negatieve emoties de invloed van verhaalversie op de intentie medieerden (action planning: $b=$ .101 , CI [.012, .263]; negatieve emoties: $b=-.076$, CI [-.211, -.011]). Lezing van het strategieverhaal leidde tot een hogere score op action planning in vergelijking met het gevaarverhaal en had via die route een positief effect op de intentie. Lezing van het gevaarverhaal leidde tot een hogere score op negatieve emoties in vergelijking met het strategieverhaal en beïnvloedde langs deze variabele de intentie. Het directe effect van verhaalversie op intentie was vervolgens niet meer significant $(b=.258$, CI $[-.043, .561])$.

\subsection{Conclusie}

De resultaten van dit onderzoek dragen bij aan ons inzicht in de wijze waarop narratieve gezondheidsinterventies invloed kunnen uitoefenen op intenties om gezonder te leven. Beide narratieve interventies hadden invloed op de intentie om meer te bewegen maar die invloed werd gerealiseerd via een andere route. Het gevaarverhaal riep meer negatieve emoties op dan het strategieverhaal en naarmate deze emoties sterker waren, leidde dat tot een positievere intentie om meer te bewegen. Het strategieverhaal riep een sterkere action planning op dan het gevaarverhaal en naarmate die planning sterker werd, leidde dat tot een positievere intentie om meer te bewegen.

De invloed die negatieve emoties en action planning hebben op de intentie is ongeveer even sterk. Toch leidde over het geheel gezien het strategieverhaal tot een positievere intentie in vergelijking met het gevaar- 
verhaal. Uit de mediatie-analyse bleek dat geen van de andere variabelen (zoals weerstand, uitvoerbaarheid, vormen van narratieve betrokkenheid) een verklaring voor dit effect vormden. Mogelijk wordt het sterkere effect van het strategieverhaal veroorzaakt doordat er meer intenders in de steekproef zaten dan non-intenders. Juist voor die eerste groep is ondersteuning van hun planningsvaardigheden van groot belang om hen aan te zetten tot gezonder gedrag. Als er meer intenders dan non-intenders in de steekproef zaten, zou het positieve effect van het strategieverhaal vaker zijn opgetreden.

Het medium bleek voor geen van de onderzochte variabelen van belang. Of het verhaal werd gelezen of beluisterd bleek geen gevolgen te hebben voor de verhaalervaring en de HAPA-determinanten. Gegeven de veronderstelde lagere gezondheidsgeletterdheid van de doelgroep en het gegeven dat Shen et al. (2015) kleinere effecten voor gedrukte narratieve gezondheidsinterventies rapporteerden, luidde de verwachting dat het auditieve verhaal het beter zou doen. Dit bleek niet op te gaan voor de vrachtwagenchauffeurs in dit onderzoek. Mogelijk speelde zelfselectie daarbij een rol. Chauffeurs die moeite hebben met lezen, zijn wellicht minder geneigd om deel te nemen aan een onderzoek waarbij ze een vragenlijst moeten invullen.

\section{$6 \quad$ Algemene discussie}

Wat betreft overgewicht, het eten van groente en fruit en voldoende beweging doen vrachtwagenchauffeurs het slechter dan de rest van werkend Nederland. Hen aanzetten tot gezonder gedrag is een belangrijk doel, voor de chauffeurs zélf die op die manier langer en langer in goede gezondheid leven maar ook voor de Nederlandse economie: de verwachting is dat in de toekomst het aantal nieuwe chauffeurs (sterk) achterblijft bij de vraag van werkgevers. Duurzame inzetbaarheid van de huidige chauffeurs is vanuit dat perspectief van groot belang.

De interventies waarmee wordt geprobeerd om chauffeurs aan te zetten tot gezonder gedrag, lijken het niet vertonen van gezonder gedrag als een motivatieprobleem te zien. Ze bevatten vooral (impliciete) argumenten die chauffeurs moeten overtuigen van de wenselijkheid van het gezonde gedrag en de risico's van hun huidig gedrag. Mogelijk slaan deze interventies daarmee de plank mis. Deze communicatiestrategie stelt hoge eisen aan de cognitieve vaardigheden van de doelgroep. Zij moeten bepalen welke informatie als argument kan dienen, verzwegen premissen infereren, het 
argumenttype identificeren en vervolgens de relevante evaluatiecriteria weten en toepassen. Daarnaast is de vraag of het niet vertonen van het gezonde gedrag wel echt een motivatieprobleem is.

Bij het experiment bleek dat narratieve interventies een interessante communicatiestrategie kunnen vormen bij het aanzetten tot gezonder gedrag. Zowel het verhaal over de gezondheidsrisico's van het huidige gedrag als het verhaal waarin strategieën voor het omzeilen van barrières werden geillustreerd, leidde - ieder op zijn eigen manier - tot een positievere intentie om meer te gaan bewegen. In dit onderzoek was geen sprake van een controlegroep. In principe is het denkbaar dat een retorische interventie een vergelijkbaar of zelfs sterker effect had bewerkstelligd; aangezien retorische campagnes in het verleden echter weinig effect hebben gesorteerd, was het niet opportuun dergelijke interventies nu in de praktijksituatie nog eens te herhalen.

Tegelijkertijd vormen de hier gerapporteerde effecten mogelijk een onderschatting van de effectiviteit van narratieve interventies. Het ligt voor de hand dat de effecten groter zouden zijn als het gevaarverhaal uitsluitend door non-intenders wordt gelezen en het strategieverhaal alleen door intenders. Idealiter zouden intenders en non-intenders aan de hand van een voormeting zijn geïdentificeerd om vervolgens het voor hen relevante verhaal aangeboden te krijgen. Een dergelijke voormeting kan echter de reactie op de interventie beïnvloeden als die er direct op volgt. Daarom is er in een vervolgstudie voor gekozen om die voormeting drie weken voor de interventie af te nemen (Boeijinga et al., in voorbereiding). Voor dat onderzoek hebben de hier gerapporteerde studies twee bouwstenen aangeleverd: wat gebeurt er eigenlijk in de huidige interventies én zouden narratieven op verschillende manieren de intentie kunnen beïnvloeden?

Opvallend is het uitblijven van een effect van het medium: de auditieve versie had volstrekt vergelijkbare effecten op alle variabelen als de geschreven versie. Hoewel dit overeenkomt met de resultaten van de meta-analyse van Braddock en Dillard (2016), werd verwacht dat de auditieve versie het beter zou doen bij deze doelgroep. Dat houdt niet in dat het medium geen rol speelt. Recent onderzoek naar de inzet van fotoverhalen voor laaggeletterde doelgroepen wijst op interessante mogelijkheden in dit verband (Koops van 't Jagt, de Winter, Reineveld, Hoeks, \& Jansen, 2016; Koops van 't Jagt, Hoeks, Duizer, et al., in druk).

Met deze onderzoeken hopen we bij te dragen aan de inzichten voor het ontwikkelen van gezondheidsinterventies die erin slagen om de gezondheidskloof tussen lager en hoger opgeleiden te verkleinen. Daarbij is van belang dat ontwerpers van dergelijke interventies zich realiseren dat 
het niet vertonen van gezonder gedrag wellicht meer het gevolg is van obstakels dan van een gebrek aan motivatie én dat narratieve interventies wellicht meer aansluiten bij de informatie- en communicatiebehoeften van de lager geletterde doelgroep.

\section{Noot}

1. Het in dit artikel beschreven onderzoek is uitgevoerd in het kader van het door NWO ZonMW gefinancierde onderzoeksproject BGRL-11-15. De auteurs bedanken Bregje Holleman, Carel Jansen en twee anonieme beoordelaars voor commentaar op eerdere versies van dit artikel.

\section{Bibliografie}

Boeijinga, A., Hoeken, H., \& Sanders, J. (2016). Health promotion in the trucking setting: Understanding Dutch truck drivers' road to health lifestyle changes. Work, 55, 385-397.

Boeijinga, A., Hoeken, H., \& Sanders, J. (2017). An analysis of health promotion materials for Dutch truck drivers: off target and too difficult? Work, 56, 539-549, DOI:10.3233/WOR-172503.

Boeijinga, A., Hoeken, H., \& Sanders, J. (in druk). The persuasive effects of risk perception-focused versus planning strategies-focused health narratives targeting Dutch truck drivers. International Journal of Communication.

Boeijinga, A., Hoeken, H., \& Sanders, J. (in voorbereiding). Dutch Truckers and Exercise: Testing the Effectiveness of Tailored Health Narratives.

Braddock, K., \& Dillard, J. P. (2016). Meta-analytic evidence for the persuasive effects of narratives on beliefs, attitudes, intentions, and behaviors. Communication Monographs, 83(4), 446-467.

Busselle, R., \& Bilandzic, H. (2009). Measuring narrative engagement. Media Psychology, 12(4), 321-347.

CBS (2010). Standaard Beroepenclassificatie 2010. Den Haag/Heerlen: Centraal Bureau voor de Statistiek. https://www.cbs.nl/nl-nl/onze-diensten/methoden/classificaties/onderwijs\% 2oen\%2oberoepen/beroepenclassificatie-isco-en-sbc-/standaard-beroepenclassificatie2010-sbc-2010-/downloaden-en-installeren-sbc-2010. Geraadpleegd op 2 februari 2017.

Centraal Bureau voor de Statistiek (CBS). (2012, 7 februari). Kloof in levensverwachting tussen hoog-en laagopgeleiden blijft even groot. https://www.cbs.nl/nl-nl/achtergrond/2012/06/ kloof-in-levensverwachting-tussen-hoog-en-laagopgeleiden-blijft-even-groot. Geraadpleegd op 2 februari 2017 .

Centraal Bureau voor de Statistiek (CBS). (2016, 18 januari). Gezonde levensverwachting; opleidingsniveau. http://statline.cbs.nl/StatWeb/publication/?DM=SLNL\&PA=71885 ned. Geraadpleegd op 2 februari 2017.

Fishbein, M., \& Yzer, M. C. (2003). Using theory to design effective health behavior interventions. Communication Theory, 14(2), 164-183.

Garssen B. (2001). Argument Schemes. In: Van Eemeren F. H. (ed.) Crucial Concepts in Argumentation Theory (pp. 81-99). Amsterdam: Amsterdam University Press. 
Graaf, A. de, Hoeken, H., Sanders, J., \& Beentjes, J. (2009). The role of dimensions of narrative engagement in narrative persuasion. Communications, 34(4), 385-405.

Graaf, A. de, Sanders, J., \& Hoeken, H. (2016). Characteristics of Narrative Interventions and Health Effects: A Review of the Content, Form, and Context of Narratives in Health-related Narrative Persuasion Research. Review of Communication Research, 4, 88-131.

Gollwitzer, P., \& Sheeran, P. (2006). Implementation intentions and goal achievement: A metaanalysis of effects and processes. Advances in Experimental Social Psychology, 38, 69-119.

Green, M. C. (2006). Narratives and cancer communication. Journal of Communication, 56(s1), S163-183.

Green, M. C., \& Brock, T. C. (200o). The role of transportation in the persuasiveness of public narratives. Journal of Personality and Social Psychology, 79(5), 701-721.

Koops van 't Jagt, R., Winter, A. de., Reijneveld, S.A., Hoeks, J.C.J., \& Jansen, C.J.M. (2016). Development of a communication intervention for older adults with limited health literacy: Photo stories to support doctor-patient communication. Journal of Health Communication, 21 (sup2), 69-82.

Koops van 't Jagt, R., Hoeks, J.C.J., Duizer, E., Baron, M., Molina, G.B., Unger, J.B., \& Jansen, C.J.M. (in druk). Sweet temptations: How does reading a fotonovela about diabetes affect Dutch adults with different levels of literacy? Health Communication., http://dx.doi.org/10.1080/ 10410236.2016.1258617.

Kreuter, M. W., Green, M. C., Cappella, J. N., Slater, M. D., Wise, M. E., Storey, D., et al. (2007). Narrative communication in cancer prevention and control: A framework to guide research and application. Annals of Behavioral Medicine, 33(3), 221-235.

Maio, G. R., Verplanken, B., Manstead, A. R., Stroebe, W., Abraham, C., Sheeran, P., \& Conner, M. (2007). Social psychological factors in lifestyle change and their relevance to policy. Social Issues and Policy Review, 1(1), 99-137.

Moyer-Gusé, E. (2008). Toward a Theory of Entertainment Persuasion: Explaining the Persuasive Effects of Entertainment-Education Messages. Communication Theory, $18(3)$, 407-425.

Schellens, P. J., \& De Jong, M. (2004). Argumentation Schemes in Persuasive Brochures. Argumentation, $18(3), 295-323$.

Schwarzer, R. (2008). Modeling Health Behavior Change: How to Predict and Modify the Adoption and Maintenance of Health Behaviors. Applied Psychology, 57(1), 1-29.

Sectorinstituut Transport \& Logistiek (STL) (2016a). Factsheet Inzetbaarheid 2015. https:// www.stlwerkt.nl/VTL/media/MediaLibrary/Instroom\%2oen\%2oDetachering/ STL5104_Factsheet_08MM_1.pdf. Geraadpleegd op 2 februari 2017.

Sheeran, P. (2002). Intention-Behavior Relations: A Conceptual and Empirical Review. European Review of Social Psychology, 12(1), 1-36.

Shen, F., Sheer, V. C., \& Li, R. (2015). Impact of Narratives on Persuasion in Health Communication: A Meta-Analysis. Journal of Advertising, 44(2), 105-113.

Sectorinstituut Transport \& Logistiek (STL) (2016b). Sectorplan Transport en Logistiek 2016-2017. https://www.stlwerkt.nl/over-ons/sectorplan-transport-en-logistiek-2016-\%E2\%80\%93-2017. Geraadpleegd op 2 februari 2017.

Toolan, M. J. (2001). Narrative: A Critical Linguistic Introduction ( $2^{\text {nd }}$ ed.). New York, NY: Routledge.

Twickler, T. B., Hoogstraaten, E., Reuwer, A., Singels, L., Stronks, K., Essink-Bot, M.L. (2009). Laaggeletterdheid en beperkte gezondheidsvaardigheden vragen om een antwoord in de zorg. Nederlands Tijdschrift voor Geneeskunde, 153: A250.

World Health Organization (WHO). (1998). Health Promotion Glossary. Retrieved from: http:// www.who.int/healthpromotion/about/HPR\%20Glossary\%201998.pdf. Geraadpleegd op 2 februari 2017. 


\section{Over de auteurs}

Hans Hoeken is hoogleraar Communicatie- en Informatiewetenschappen aan de Universiteit Utrecht bij het Departement Talen, Literatuur en Communicatie en bij het Utrechts Instituut voor Linguïstiek OTS.

E-mail: j.a.l.hoeken@uu.nl.

Anniek Boeijinga is promovenda aan de Radboud Universiteit bij het Centre for Language Studies.

E-mail: a.boeijinga@let.ru.nl.

José Sanders is hoogleraar Narratieve Communicatie aan de Radboud Universiteit bij het Centre for Language Studies.

E-mail: j.sanders@let.ru.nl. 